\title{
MUDRÁK JÓZSEF
}

\section{A DEBRECENI KOSSUTH LAJOS TUDOMÁNYEGYETEM ARCHONTOLÓGIÁJA 1950-1990 \\ XV. (befejező) rész*}

A Kossuth Lajos Tudományegyetem két kara, a Bölcsészettudományi Kar és a Természettudományi Kar, valamint az ún. központi egységek 1950. január 1. és 1990. december 31. közötti archontológiáját a Rektori Hivatal személyi kartotékjai és anyagai, valamint a kevésbé dokumentált '50-es évek tekintetében kiegészitöleg a Személyzeti Osztály éves kimutatásai alapján készült. Ennek ellenére a rendelkezésünkre álló anyag nem lehet teljes és nem lehetséges teljes pontossággal összeállitani az archontológiát. Jelen XV. rész az Idegennyelvi Lektorátus dolgozóinak listáját adja a lektorátus vezetötöl az ügyintézőíg.

Kulcsszavak: Kossuth Lajos Tudományegyetem, archontológia, Idegennyelvi Lektorátus, nyelvoktatás

The Archontology of Lajos Kossuth University of Arts and SCIENCES (1950-1990), Part XV: LeCtorate OF FOREIGN LANGUAGES. The Archontology of Kossuth University for the School of Arts, the School of Sciences, and for the so-called "Central Units" between January 1, 1950, and December 31, 1990, was compiled on the basis of the personal cards and personal files of the Personnel Department of the Rector's Office, and the scantily documented section for the 1950s was supplemented from the annually arranged documentary material of the Personnel Office. Even so, however, the existing material fails to be complete. It is impossible to compile the archontology with perfect accuracy. Part XV presents the complete list pertaining to the Lectorate of Foreign Languages from head of department to administrator.

Keywords: Lajos Kossuth University of Arts and Sciences, archontology, Lectorate of Foreign Languages, Education of Foreign Languages

\section{IDEGENNYELVI LEKTORÁTUS} (1954. VIII. 1-töl 1983. VI. 30-ig csak BTK)

\section{Vezetö}

Dr. Koczogh Ákosné Huszár Katalin 1952. VIII. 22.-1954. VII. 31.

Korponay Béla

1954. VIII. 1.-1955. VIII. 15.

Hadas Ferenc

1955. VIII. 16.-1957. VII. 31.

* A KLTE bölcsészettudományi kari, természettudományi kari és ún. központi egységeinek 1950. jan. 1. - 1990. dec. 31. közötti archontológiája a Rektori Hivatal Személyzeti Osztályának személyi kartonjai és személyi dossziéi alapján készült, kiegészítve a kevéssé dokumentált 1950-es éveket illetően a Személyzeti Osztály évrendezett iratanyagaival. A meglévő anyagok azonban így sem teljesek, ezért az archontológiát százszázalékos pontossággal összeállítani nem lehetséges.

(Jelzések: $\mathrm{H}=$ helyettes, $\mathrm{M}=$ megszakításokkal, $\mathrm{MÁ}$ = másodállásban, $\mathrm{NY}=$ nyugdíjasként, $50 \%$ = félállásban, mb. = megbízott, tszcsp = tanszékcsoport) 
Dr. Dombrovszky Józsefné Nagy Ilona 1964. IX. 1.-1983. VI. 30.

Dr. Nyirkos Istvánné dr. Kiss Edit 1983. VII. 1.-

Dr. Nábrádi Zoltánné

dr. Ruszkay Julianna

1988. IX. 1.-1988. XII. 31. (mb.)

Nyelvtanár

Simon Emilné

1951. II. 1.-1954. VIII. 15.

Dombrovszky Józsefné Nagy Ilona

1951. IX. 1.-1954. VII. 31.

Dr. Koczogh Ákosné Huszár Katalin 1951. XI. 1.-1954. VII. 31.

Dr. Nyirkos Istvánné dr. Kiss Edit

1952. VII. 1.-1954. VII. 31.

Nagy Magdolna

1953. VII. 1.-1954. VII. 15.

Dr. Pősze Lajosné Fésüs Katalin

1953. VII. 1.-1955. VI. 30.

Spilevaja Irina

1953. VII. 1.-1953. VIII. 31.

Dr. Fejes Andor

1954. VIII. 15.-1955. VIII. 31.

Korponay Béla

1955. VIII. 1.-1957.

Dr. Dombrovszky Józsefné Nagy Ilona

1955. IX. 1.-1983. XII. 26.

Dr. Iglói Endréné Balogh Marianna

1965. XI. 1.-

Pogány Andorné Demkó Tatjána

1971. I. 1.-1985. VIII. 31.

Dr. Nábrádi Zoltánné Ruszkay Julianna 1975. VII. 15.-

Dr. Oláh Lajos

1977. IX. 1.-1984. V. 16.

Ládi József

1978. VII. 16.-

Dr. Orosz Lászlóné Sasvári Ildikó

1981. VII. 1.-

Lőrincziné dr. Ferenczfalvi Éva

1982. VII. 1.-

Dr. Gebei Sándorné Pancsenko Anna 1982. VIII. 1.-

Bereczki Tiborné Győrfi Katalin

1982. IX. 1.-1982. XII. 31. (H)

Dr. Erdei Gyula

1983. VII. 1.-

Dr. Hatvani Istvánné Bognár Ilona

1983. VII. 1.-

Kiss Gézáné Buzáky Judit

1983. VII. 1.-

Kornya László

1983. VII. 1.-

Kozma Andrásné Németh Lenke

1983. VII. 1.-

Dr. Ménes Andrásné Tóth Éva

1983. VII. 1.-

Dr. Nyirkos Istvánné dr. Kiss Edit

1983. VII. 1.-

Dr. Pelyvás-Ferenczik István

1983. VII. 1.-1986. XII. 31.

Dr. Pelyvás-Ferenczik Péter

1983. VII. 1.-

Rovny Ferenc

1983. VII. 1.-

Szabó-Pap Judit

1983. VII. 1.-

Dr. Szabó Imréné Enyedi Gabriella

1983. VII. 1.-

Dr. Végvári József

1983. VII. 1.-

Drahos József, ifj.

1983. IX. 1.-

Dr. Havas Lászlóné Deák Gyöngyi

1983. IX. 1.-

Dr. Lovas Rezsőné dr. Rózsa Olga

1983. IX. 1.- 
Dr. Nyilas Istvánné Török Györgyi

Murtha, John Patrick

Dr. Oláh Lajos

Csontos Pál

Dávid Gyula

Sankó Gyula

Csontos Pál

Mónos Katalin

Dr. Nyilas Istvánné Török Györgyi

Czellér Andrásné Farkas Mária

Lovas Sándorné Hangácsi Margit

Dr. Nyilas Istvánné Török Györgyi

Pogány Andorné Demkó Tatjána

Vasas László

Miklódy Éva

Schvetsné Nagy Magdolna

Dr. Hajnády Zoltánné Czimmer Teréz

Agárdi Zsuzsa

Kulcsár Dezső

Machmutova Szvetlana

Dr. Pelyvás-Ferenczik István

Deilinger Judit

Dr. Jagusztin László

Kleewein, Hannelore

Kosztyu Jánosné Müller, Elke

Vasas László

Császár Judit

\section{Könyvtáros ügyintéző}

Kisné Kálmánczhey Ágnes

Kissné Bertalan Irén

Kissné Bertalan Irén
1983. IX. 1.-1983. XII. 31. (MÁ) ${ }^{1}$

1984. I. 1.-

1984. V. 16.-1988. I. 31. (MÁ) ${ }^{2}$

1984. IX. 1.-1984. XII. 31. (MÁ)

1984. IX. 1.-1990. VIII. 15.

1984. X. 1.-1984. X. 31. (MÁ) ${ }^{4}$

1985. II. 1.-1985. V. 31. (MÁ)

1985. II. 1.-1985. V. 31.

1985. II. 1.-1985. V. 31. (MÁ)

1985. IX. 1.-

1985. IX. 1.-

1985. IX. 1.-

1985. IX. 1.-1988. VI. 30. (NY)

1985. IX. 1.-1986. V. 31. (M) (MÁ)

1986. III. 1.-1987. VIII. 31. (H)

1986. III. 1.-1986. V. 31. (MÁ) ${ }^{6}$

1986. V. 1.-1986. VI. 30. (H) (MÁ) ${ }^{7}$

1986. IX. 11.-1986. XII. 31. (H)

1987. II. 1.-1987. V. 31. (H) (MÁ) ${ }^{8}$

1987. II. 1.-1987. V. 31. (MÁ) ${ }^{9}$

1987. II. 1.-1988. VI. 30. (M) (NY)

1987. IX. 1.-

1987. IX. 1.-1989. V. 31. (M) (MÁ) ${ }^{10}$

1989. IX. 1.-? (H)

1989. IX. 1.-

1990. VIII. 1.-

1990. IX. 1.-

1983. VII. 1.-1987. X. 17.

1984. VI. 1.-1985. XII. 31.

1986. I. 1.-1986. I. 31. (MÁ) $)^{11}$

${ }^{1}$ Dr. Nyilas Istvánné Török Györgyi fơállása: a Kun Béla Kollégium nevelőtanára.

2 Dr. Oláh Lajos foállása: a Hazafias Népfront Városi Bizottságának titkára.

3 Csontos Pál fóállása: a Liszt Ferenc Téri Gimnázium tanára.

${ }^{4}$ Sankó Gyula főállása: a Tóth Árpád Gimnázium tanára.

5 Vasas László fóállása: az Agrártudományi Egyetem oktatója.

${ }^{6}$ Schvetsné Nagy Magdolna fóállása: az Ybl Miklós Műszaki Főiskola nyelvtanára.

7 Dr. Hajnády Zoltánné Czimmer Teréz fóállása: a Német Tanszék könyvtárosa.

${ }^{8}$ Kulcsár Dezső fóállása: a DOTE Idegennyelvi Lektorátusán nyelvtanár.

9 Machmutova Szvetlana fóállása: a DATE nyelvtanára.

${ }^{10}$ Dr. Jagusztin László főállása: az Orosz Irodalmi Tanszék docense.

${ }^{11}$ Kissné Bertalan Irén foállása: a Klasszika-Filológiai Tanszéken ügyintéző. 


\section{Adminisztrátor-ügyintéző}

Juhász Zsigmondné Székely Mária

1983. X. 17.-1987. XII. 31. (M) (NY)

Juhász Zsigmondné Székely Mária

1989. I. 1.-1989. XII. 31. (NY)

Könyvtáros adminisztrátor

Gólya Istvánné Majoros Gizella

1987. XII. 1.-

Gépíró adminisztrátor

Sári Margit

1988. VII. 1.-

\section{TTK IDEgenNyelVI LeKTORÁTUS (1954. VIII. 1-töl 1983. VI. 30-ig)}

\section{Vezető}

Dr. Koczogh Ákosné Huszár Katalin 1954. VIII. 1.-1958. VI. 30.

Dr. Pősze Lajosné Fésüs Katalin 1958. IX. 29.-1975. VI. 30.

Dr. Nyirkos Istvánné dr. Kiss Edit 1975. VII. 1.-1983. VI. 30.

\section{Nyelvtanár}

Dombrovszky Józsefné Nagy Ilona 1954. VIII. 1.-1955. VIII. 31.

Dr. Koczogh Ákosné Huszár Katalin 1954. VIII. 1.-1958. VI. 30.

Nagy László 1954. VIII. 1.-1955. VI. 30.

Dr. Nyirkos Istvánné dr. Kiss Edit 1954. VIII. 1.-1983. VI. 30.

Dr. Pősze Lajosné Fésüs Katalin 1955. VII. 1.-1980. VI. 30.

Vaszili Pál

1955. VII. 16.-1960. III. 31.

Kiss Gézáné Buzáky Judit

1960. VIII. 1.-1983. VI. 30.

Hegedüs Imréné Iljina Lidia

Vaszili Pál

1962. IX. 1.-1963. I. 31. (MÁ) ${ }^{12}$

Hegedüs Imréné Iljina Lidia

1962. XI. 1.-1965. VII. 31.

Dr. Pelyvás-Ferenczik István

1963. II. 1.-1964. VI. 30.

Fazekas Sándor

Dr. Erdei Gyula

1963. VIII. 1.-1983. VI. 30.

Dr. Iglói Endréné Balogh Marianna

1964. II. 1.-1964. V. 31. (MÁ) ${ }^{13}$

1964. III. 1.-1983. VI. 30.

Fazekas Sándor

1964. VII. 1.-1965. X. 31.

Koós Katalin

1964. IX. 1.-1965. V. 31. (MÁ)

Kornya László

1965. VIII. 15.-1967. VII. 31. (H)

1965. IX. 1.-1983. VI. 30.

\footnotetext{
${ }^{12}$ Hegedüs Imréné Iljina Lidia fóállása: az Egyetemi Könyvtár könyvtárosa.

13 Fazekas Sándor foállása: a Csokonai Vitéz Mihály Gimnázium igazgatóhelyettese.
} 
Dr. Ménes Andrásné Tóth Éva

Dr. Lovas Rezsőné Rózsa Olga

Czellár Sándorné Csiba Judit

Dr. Kara Pálné dr. Pogány Tatjána

Lengyel Zsolt

Dr. Kara Pálné dr. Pogány Tatjána

Dr. Hatvani Istvánné Bognár Ilona

Dr. Pelyvás-Ferenczik Péter

Rovny Ferenc

Végvári József

Szabó-Pap Judit

Kozma Andrásné Németh Lenke

Dr. Szabó Imréné Enyedi Gabriella

Adminisztrátor

Nagy Klára

Juhász Zsigmondné Székely Mária

Adminisztratív ügyintéző

Budai Lászlóné Komjáthi Róza

Juhász Zsigmondné Székely Mária

Könyvtáros ügyintéző

Kisné Kálmánczhey Ágnes

Tudományos ügyintéző

Tayler, Nicholas
1965. IX. 12.-1983. VI. 30.

1971. I. 1.-1973. IX. 30. (?) (MÁ) $)^{14}$

1973. X. 1.-1973. XI. 30. (MÁ) $)^{15}$

1974. II. 1.-1974. V. 31. (MÁ) ${ }^{16}$

1974. II. 1.-1974. V. 31. (MÁ) ${ }^{17}$

1975. II. 1.-1975. V. 31. (MÁ)

1975. VII. 1.-1983. VI. 30.

1975. VII. 1.-1983. VI. 30.

1977. VIII. 15.-1983. VI. 30.

1980. I. 1.-1983. VI. 30.

1980. VII. 1.-1983. VI. 30.

1981. VII. 1.-1983. VI. 30.

1981. VII. 1.-1983. VI. 30.

1964. V. 15.-1967. XI. 15.

1977. IX. 1.-1979. XII. 31. (NY)

1970. I. 15.-1976. XII. 31.

1975. I. 1.-1977. VIII. 31. (NY)

1981. V. 1.-1983. VI. 30.

1982. IX. 1.-1982. XII. 31.

${ }_{14}$ Dr. Lovas Rezsőné Rózsa Olga fóállása: a DOTE II. sz. Belgyógyászati Klinika könyvtárosa.

${ }^{15}$ Czellár Sándorné Csiba Judit fóllása: a Vígkedvű Mihály Âltalános Iskola tanára.

${ }^{16}$ Dr. Kara Pálné dr. Pogány Tatjána fóállása: a Kölcsey Ferenc Református Tanítóképző Főiskola dolgozója.

${ }^{17}$ Lengyel Zsolt fóállása: az Ybl Miklós Műszaki Főiskola nyelvtanára. 